\title{
Aneuploidy Analysis of 5740 Referral Cases: A Triennial Report
}

\author{
Nidhi P. Shah ${ }^{1}$, Parth S. Shah ${ }^{1}$, Nirzari H. Bhatt ${ }^{1}$, Ketan K. Vaghasia ${ }^{1}$, Krishna Mistry ${ }^{1}$, Jeanny Dominic ${ }^{1}$, \\ Sandip C. Shah ${ }^{1}$, Mandava V. Rao ${ }^{* 1,2}$ \\ ${ }^{1}$ Neuberg Supratech Referral Laboratory, "Kedar” Building, Opposite Krupa Petrol Pump, Near Parimal Garden, \\ Ellisbridge, Ahmedabad 380 006, Gujarat, India \\ ${ }^{2}$ School of Sciences, Gujarat University, Ahmedabad 380 009, Gujarat, India,
}

*Corresponding Author: Mandava V. Rao; manvrao@gmail.com

Received 31 January 2020;

Accepted 16 February 2020;

Published 20 February 2020

\begin{abstract}
Background and Objectives: Aneuploidy is one of the major concerns to cause genetic anomalies. This condition is mostly related to addition and/or deletion with respect to set(s) of chromosomes. Here, we report an analysis of 5740 referral cases during three consecutive years (2015 2018) from our Diagnostic Research Center, Ahmedabad for aneuploidy pattern. Methodologies: The patients were asked to fill the necessary forms and their blood $(5 \mathrm{ml})$ was drawn for chromosomal studies using the Karyotyping following International System for Human Cytogenetic Nomenclature (ISCN) manual. Results: The data revealed the numerical aberrations for only aneuploidy detected was (3.7\%; $211 / 5740)$. In this report, constitutional (c) autosomal aneuploidy was $75 \%(158 / 211)$. The total mosaic cases were nine $(9 / 211)$ comprising constitutive $(2)$ and acquired (7) aneuploidy cases. In autosomal aneuploidy, cT21 was higher $(96 \% ; 152 / 158)$ than others $(4 \% ; 6 / 158)$ comparatively. Among cT21 (152), males $(76 \% ; 115 / 152)$ were more affected than females $(24 \% ; 37 / 152)$. These statistical data also revealed that acquired chromosomal aneuploidy (leukemia) possessed (25\%; 53/211); with more mosaic cases $(7 / 211)$. Conclusion: Couples with such conditions are eligible for genetic tests and counseling as well as new strategies are urgently to be undertaken by governmental organizations (GOs) and non-governmental organizations (NGOs) for affected families with better personalized and informed decision making. The significance of these data is thus discussed in relation to genetic disorders caused by constitutional and acquired aneuploidy of leukemic blood in this report.
\end{abstract}

Keywords: Human, Blood, Karyotyping, Mosaicism, Constitutional and Acquired Aneuploidy

\section{Introduction}

Variations from the normal diploid state involve changes (addition/deletion) in number of single chromosomes rather than of haploid sets, are aneuploids. Large variations from normal pattern lead to non-viable fetuses that need to be aborted in first trimester, but small variations from this state can lead to birth of a child with varying type of birth defects depending on nature of chromosome involved in the balance. ${ }^{[1,2,3]}$ Chromosomal etiology is very common in miscarriages, since $50 \%$ of first trimester pregnancy loss are due to chromosomal abnormalities like aneuploidy condition in the fetus. ${ }^{[4]}$ Hence a routine chromosomal analysis is used as a starting point for the diagnosis of cytogenetic investigation of congenital malformations and developmental delays or mental retardation in children, reproductive delays and failures in adults. ${ }^{[5]}$ This condition has a significant role in creation of genetic diseases with a battery of phenotypic dysfunctions. ${ }^{[6,7]}$ Actually chromosomal aneuploidies are catastrophic for development and have been reported for all chromosomes in spontaneous abortions. In humans, aneuploidy is surprisingly common occurring in about $4 \%$ of clinically recognized pregnancies. ${ }^{[8]}$ It is also evident that loss of a chromosome (monosomy) is much more detrimental than gain (trisomy) of a chromosome. Monosomy $\mathrm{X}$ is the non - mosaic monosomic condition that is compatible with life and is largely attributed to $\mathrm{X}$ chromosome inactivation. The trisomic states of $13,18,21, \mathrm{X}$ and $\mathrm{Y}$ can survive to term. Nevertheless, it is noted that while aneuploidy for these chromosomes is compatible with live birth, the vast majority will be spontaneously aborted. However, aneuploidies are mostly maternal in origin. As it is difficult to study female gametes, sperm aneuploidy is increasingly studied. ${ }^{[8]}$ Detection of constitutional aneuploidies plays a role in prenatal genetic screening (PGS), pre-implantation genetic diagnosis (PGD) and other assisted reproductive technologies and cancer in human. ${ }^{[8,9,10]}$

Acquired chromosomal aneuploidy has been recognized as a common character of cancer cells for more than 100 years and is frequently noted in solid tumors and occasionally a few ovarian cancers and prostatic carcinomas in addition to leukemia. In hematologic malignancies, aneuploidy condition is related to gain of a chromosome rather loss of it. ${ }^{[11,12]}$ However other studies reported monosomies are important and dependent on other factors like age. ${ }^{[13,14,15]}$ 
These aneuploidies are detected by several techniques like karyotyping, FISH, multi-color FISH, Spectral karyotyping, Flow cytometry, Image Cytometry and, QF-PCR. It frequently results from errors of the mitotic check point and the major cell cycle control mechanism leading to chromosome miss-segregation at mitosis and meiosis levels. ${ }^{[10,16-20]}$ Aneuploidy also plays a role in genesis of chromosomal anomalies due to other various factors. ${ }^{[21,22,23]}$ Hence, we report an analysis of 5740 referral cases to detect constitutive (congenital) and acquired chromosomal aneuploidy during last three consecutive years that is April 2015 to March 2018 in our Diagnostic Research Center, Ahmedabad.

\section{Materials and Methods}

The referral cases of both sexes were asked to fill the consent form after informal discussion. Then $5 \mathrm{ml}$ blood including leukemic blood of these patients was taken for chromosomal analysis. Accordingly, these samples were processed using ISCN manuals for leukemic or non-leukemic blood samples. ${ }^{[24]}$ Metaphase plates of minimum 25 were analyzed for karyotyping using G-banding in our Neuberg Supratech Referral Laboratory, Ahmedabad.

The karyotypes were classified into constitutive and acquired chromosomal aneuploidy with mosaicism. These data were calculated after analysis of all referral cases in this study during these three consecutive years. Percent of each aneuploidy type was also calculated.

\section{Results}

Analysis of 5740 referral cases, 211 was detected positive for chromosomal aneuploidy $(3.7 \% ; 211 / 5740)$. The constitutional autosomal aneuploidy had $(75 \% ; 158 / 211)$ with two mosaic cases. In this group, cT21 had higher percentage $(96 \% ; 152 / 158)$. Males with constitutional (c) trisomy 21 (cT21) had 76\%, which were dominated (115/152), where as females contributed only (24\%; 37/152) (Table-1). The karyotype of cT21 female was presented (Fig. 1a). Others $(4 \% ; 6 / 211)$ were cT18, cT13, double trisomy 9 , 21 and mosaic cT21. The age of this aneuploidy ranged from day 1 to 30 years (Table-1).

The present acquired aneuploidy was $25 \%$ (53/211). Most of these cases ranged in age from 14 to 88 years. This category consisted of monosomy $7,10, \mathrm{X}$ and trisomy $8,10,11, \mathrm{X}$ and double trisomy 8,17 as well as others (Table-2). These acquired aneuploidy cases had higher mosaics (7/211) among all $(4.3 \%$; 9/211). The age ranged from 14-88 years (Table-2). Two karyotypes were presented in this aneuploidy groups (Figs. 2a,b and 3a,b).

Table 1: Constitutional/ congenital aneuploidy $(\mathrm{N}=158)$ in our referral cases $(\mathrm{N}=211)$

\begin{tabular}{|l|l|l|}
\hline Age $($ Years $)$ & Karyotype & Condition \\
\hline 1 day -35 yrs & $47, \mathrm{XX},+21(37)^{*}$ & Down Syndrome \\
\hline 2 day -13 yrs & $47, \mathrm{XY},+21(115)$ & Down Syndrome \\
\hline 21 days & $47, \mathrm{XX},+18(1)$ & Edward Syndrome \\
\hline 1 yrs & $46, \mathrm{XY} / 47, \mathrm{XY},+21(1)$ & Mosaicism with Trisomy 21 \\
\hline $30 \mathrm{yrs}$ & $46, \mathrm{XY} / 48, \mathrm{XY},+21,+21(1)$ & Mosaicism with Tetrasomy 21 \\
\hline $7 \mathrm{yrs}$ & $47, \mathrm{XX},+13(1)$ & Constitutional Patau Syndrome \\
\hline $5 \mathrm{yrs}$ & $47, \mathrm{XY},+13(1)$ & Constitutional Patau Syndrome \\
\hline $13 \mathrm{yrs}$ & $48, \mathrm{XY},+9,+21(1)$ & Double T9, T21 \\
\hline
\end{tabular}

Numbers in brackets indicate cases; Total Percent: 158/211 = 75\%; cT21Males (76\%:115/152): cT21 Females (24\%: 36/152) Gender ratio. $M ; F=3.2 ; 1.0$; Mosaics. $2 / 158$

* Karyotype given

Table 2: Acquired chromosomal aneuploidy (leukemia) with $(\mathbf{N}=53)$ in our referrals $(\mathbf{N}=\mathbf{2 1 1})$

\begin{tabular}{|l|l|l|}
\hline Age $($ Years $)$ & Karyotype & Condition \\
\hline $30-74$ & $45, \mathrm{XX},-7(8)$ & Monosomy 7 \\
\hline 35 and 57 & $45, \mathrm{XY},-7(2)^{*}$ & Monosomy 7 \\
\hline 16.7 & $46, \mathrm{XY} / 45, \mathrm{XY},-7(1)$ & Mosaic Monosomy 7 \\
\hline $35-74$ & $47, \mathrm{XY},+8(5)$ & Trisomy 8 \\
\hline 88 & $46, \mathrm{XY} / 47, \mathrm{XY},+8(1)$ & Mosaic Trisomy 8 \\
\hline 26 & $47, \mathrm{XX},+8(1)$ & Trisomy 8 \\
\hline 63 & $47, \mathrm{XY},+10(1)$ & Trisomy 10 \\
\hline 13 & $45, \mathrm{XY},-10(1)$ & Monosomy 10 \\
\hline 34 & $47, \mathrm{XX},+11(1)$ & Trisomy 11 \\
\hline 74 & $46, \mathrm{XY} / 47, \mathrm{XY},+11(1)$ & Mosaic Trisomy 11 \\
\hline 67 & $47, \mathrm{XY},+11(1)$ & Trisomy 11 \\
\hline 85 & $48, \mathrm{XX},+8,+17(1)$ & Double Trisomy 8,17 \\
\hline $17-40$ & $47, \mathrm{XXY}(13)$ & Klinefelter Syndrome \\
\hline 14 & $47, \mathrm{XXX}(1)^{*}$ & Meta female \\
\hline $18-76$ & $45, \mathrm{XO}(11)$ & Turner Syndrome \\
\hline 83 & $45, \mathrm{XO} / 46, \mathrm{XY}(1)$ & Mosaicism with Turner \\
\hline 56 & $47, \mathrm{XXY} / 47, \mathrm{XXX}(1)$ & Mosaicism, Ambiguous \\
\hline $14 \& 60$ & $47, \mathrm{XXY} / 46, \mathrm{XY}(2)$ & Mosaicism with Klinefelter syndrome \\
\hline
\end{tabular}

Numbers in brackets indicate cases; Total Percent: $53 / 211=25 \%$; Mosaics $=07 / 53$

*Karyotypes Given 
Fig. 1a: Metaphase 47,XX,+21

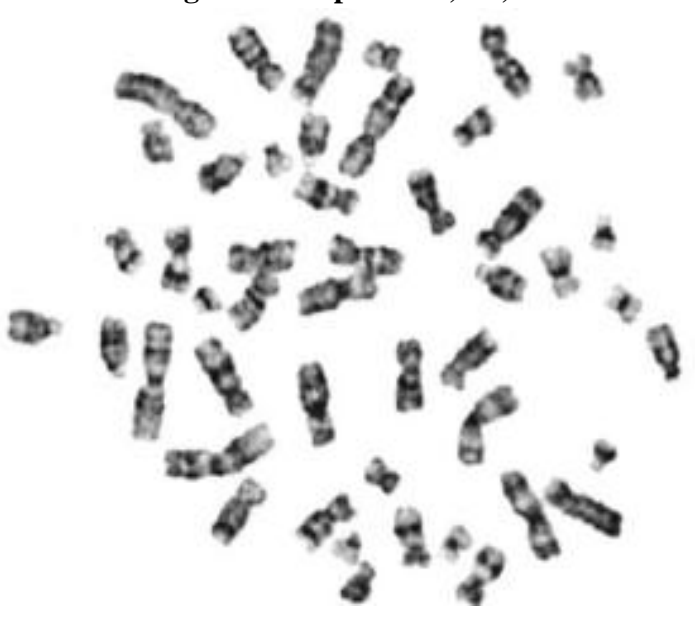

Fig. 2a: Metaphase 47,XXX

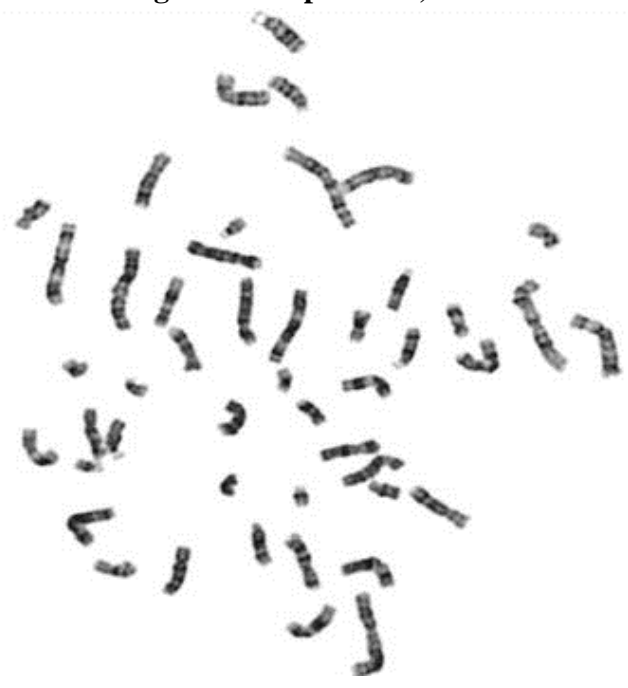

Fig. 3a: Metaphase 45,XY,-7

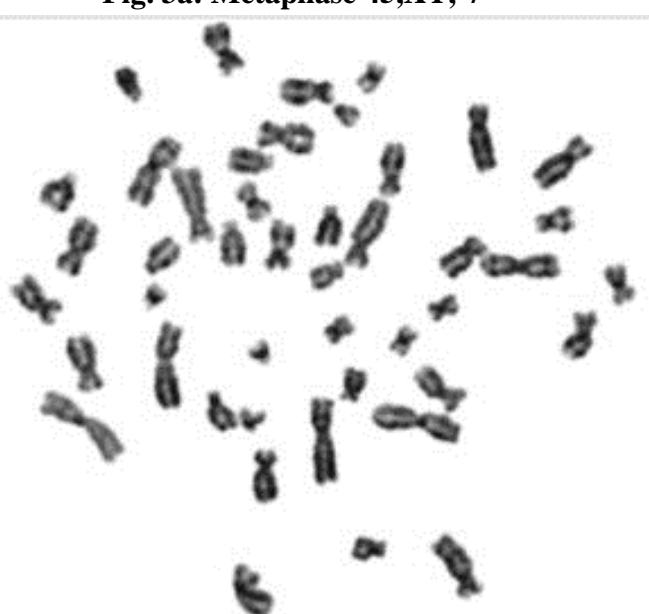

Fig. 1b: Karyogram 47,XX,+21

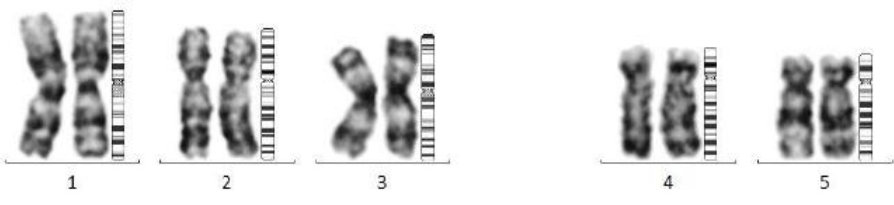

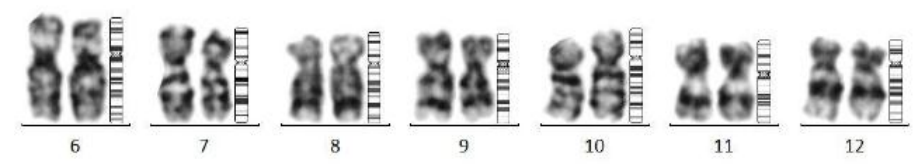

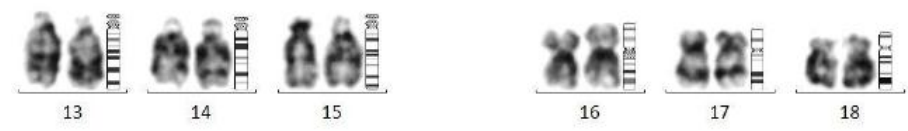

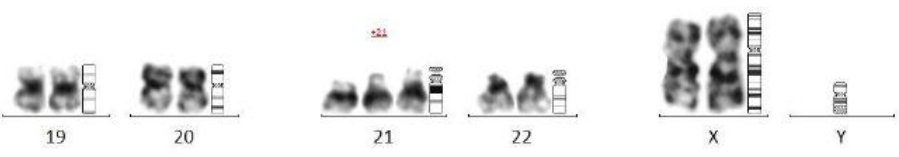

Fig. 2b: Karyogram 47,XXX

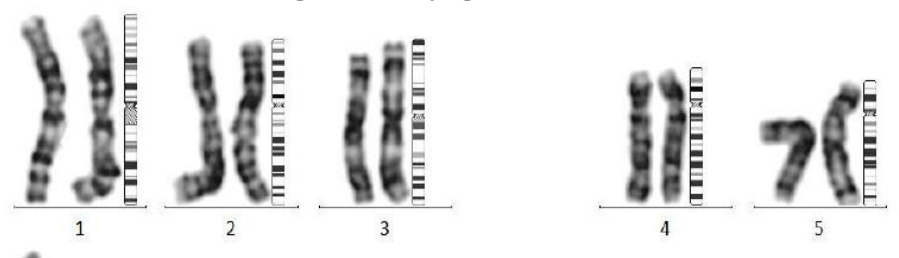

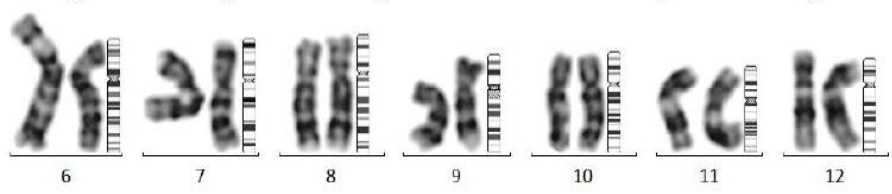

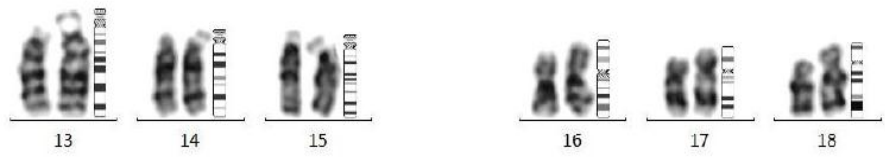

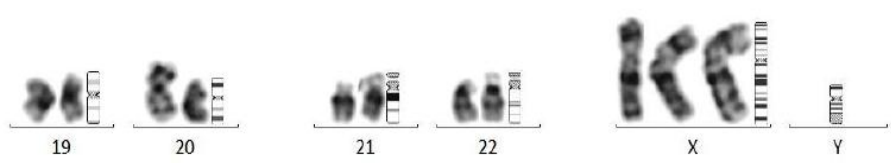

Fig. 3b: Metaphase 45,XY,-7

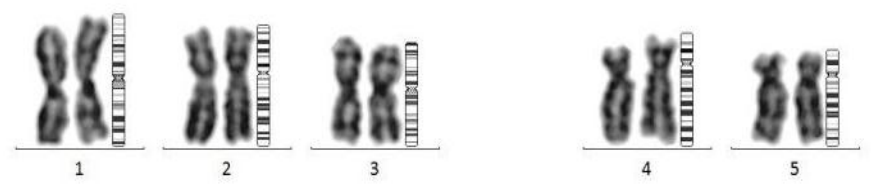

86 8.

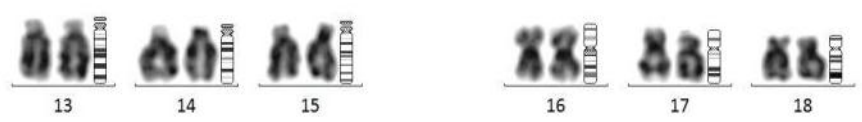

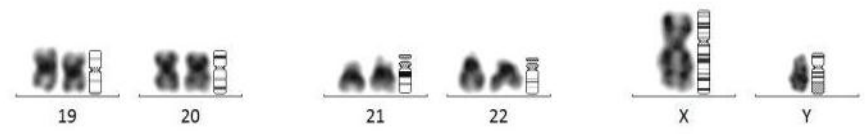

Fig. 1 a, b: Representative metaphase and karyotype of autosomal aneuploidy $(47, \mathrm{XY},+21)$

Fig 2 a, b: Representative metaphase and karyotype of constitutional gonosomal aneuploidy (47,XXX)

Fig 3 a, b: Representative metaphase and karyotype of acquired chromosomal aneuploidy 45,XY,-7 


\section{Discussion}

According to WHO report ${ }^{[4]}$ on diseases in developing world, genetic and congenital disorders are the second most common cause of infant and childhood death occurring with a birth prevalence of $2.5-6 \%$ : Our study falls in this range (3.7\%) having abnormal karyotypes. We studied their aneuploidies divided into constitutional (congenital) and acquired (cancer types). Constitutional aneuploids can support cancer ${ }^{[14]}$ as numerical chromosomal aberrations might play a role in oncology in addition to age and other factors. In our study constitutional autosomal aneuploidy consisted of hypo-and hyper-diploidies with mosaicism $75 \%$ (158/211). These reflects on dominance of cT21 (constitutional T21, Down Syndrome) among others in our study, in support of earlier workers ${ }^{[14,15]}$. These cares are contributory to neoplasms like ALL/ AML additional to phenotypic characters. ${ }^{[14]}$ Out of cT21 (152), males were dominant with high percent $(76 \%$; $115 / 152$ ) as compared to females $24 \% \%$; 37/152). This male dominance of cT21 (Down) is due to several factors including advanced age of mother, parity non chromosomal disjunction, translocation and others. Vaghasia et al. ${ }^{[25]}$ also found in their study that males were more affected where male to female ratio was 2.5:1. Similarly, in our report $\mathrm{T} 21$ of $\mathrm{T} 21$ males were more with ratio of 3.2:1. This could also be due to genetic mechanism of male predominance and chromosome non disjunction during second meiotic division of oogenesis. ${ }^{[22,25]}$ Similarly, Rajasekhar et al. ${ }^{[4]}$ documented the dominance of T21 (Down Syndrome) is associated with identifiable cause of learning disability: the most common anomaly in all trisomies including malignancies and also the most frequency $(57 \%)$ of all abnormalities related with lower age, though life span is 60 years as detected in our study. ${ }^{[26]}$ They also found high frequency of males affected. Papp et al. ${ }^{[27]}$ too detected similar results. One case was mosaic T21 (cT21M) occurring with non disjunction ${ }^{[28]}$ which can be identified by FISH in 30 years old contributing to cancer and other one was rare case of tetrasomy 21 with mosaicism having malignancies as detected in this study. Mosaic T21 had typical DS phenotypic symptoms also. One more case $^{[3]}$ was double trisomy 9 and 21 in our study which too had DS features leading to ALL. Gain of chromosome 21is Down syndrome with cancer. ${ }^{[3]}$ Trisomy is reported to have less number of malignant tumors ${ }^{[29]}$ and contributes to AML. ${ }^{[30,31]}$ This developmental delay is among the commonest problem encountered in community practice. Laboratory tests are not a substitute for evaluation of a child with global developmental delay, but are useful deforming etiology. ${ }^{[32]}$ Molecular analysis/ probe tests need to be developed to identify such problems including cancer type. ${ }^{[10]}$

Constitutional T18 (cT18, Edward) observed 1 in 7500 live births was found only one case with an age of 21 days old female. The normal life expectancy is about 1 year with numerous anomalies and neoplasms like hepatoma and Wilm's tumors are noted in them ${ }^{[14,15]}$ to support our data for constitutional autosomal aneuploidy. Such cases are prone to have ALL malignancy. Constitutional autosomal aneuploidy of cT13 cases detected were two with 5 and 7 years of male and female. Life span of these cases $(10 \%)$ are to 8 years. ${ }^{[33]}$ These cases showed severe phenotypic anomalies. Additionally such cases too possessed neoplasmic condition in support of Jackson-Cook. ${ }^{[15]}$ It's frequency is $1 / 10,000$ to $1 / 20,000 .{ }^{[29]}$ Thus cT13 and cT18 cases are considered to be lethal. ${ }^{[34,14]}$

Acquired chromosomal aneuploidy contributed to $25 \%$ (53/211). All these cases exhibited various types of blood cancer like chronic myeloid leukemia (CML), acute myeloid leukemia
(AML), myelodysplasticsyndrome (MDS), acute lymphoid leukemia (ALL)of myeloproliferative and lymphoproliferative disorders. Acquired gonosomal aneuploidy had a percent of 55\% (29/53) consisting of Turner syndrome (11) with one mosaic case (1). Klinefelter syndrome cases were 13 with two mosaic (2) following one each of meta female (1) and mosaic mixed ambiguous case (1). Presence of extra sex chromosomes can lead to hematologic malignancies like ALL. ${ }^{[3]}$

Turner's syndrome (TS) affects about 1/2800 females born alive. The syndrome results from total or partial loss of one of the two $\mathrm{X}$ chromosomes in normal existing females. In our study 11 such cases were detected having sex chromosomal aneuploidy, which is to be noted. These cases had short stature with primary and secondary amenorrhea with dysfunctional ovary as reported by others ${ }^{[10,20,35,36]}$ where considerable cytogenetic data are available in literature. Rajasekhar et $a l^{[4,5]}$ studied chromosomal abnormalities contributing to $45.2 \%$ in these cases. Thus, it is clear that loss of a chromosome (monosomy) is much more dangerous than gain (trisomy) of a chromosome. ${ }^{[8,10,37-40]}$ A cohort study of 3425 women with TS had cancer risk like tumor in CNS, breast cancer and gonadoblastoma. Mosaic TS case also had risk of malignant diseases occurring with typical $\mathrm{TS}^{[14]}$ as found in our leukemic blood sample.

Further, 13 cases were of Klinefelter syndrome with a karyotype of 47, XXY who are taller and their IQ was down withmental retardation. In population, its frequency is 1:500 to 1:1000 males depending upon two or more $\mathrm{X}$ chromosomes. ${ }^{[26]}$ These cases show infertility with small testicles having male hormone reduction. ${ }^{[10,20,26]}$ Typical KS and KS with mosaicism (2) increased tendency of lung cancer, breast cancer and other non Hodgkin lymphomas. ${ }^{[14]}$ In our study, these cases also exhibited leukemia symptoms. Other mosaic cases were (2) one each mosaic of ambiguous genitalia and meta female. Ambiguous genitalia are congenital physical abnormality where the outer genitals do not have typical appearance of either sex. This results a problem in society during rearing ${ }^{[4,5]}$ supporting the present data. The meta females (1:1000) with kidney problem are rare cases with hematological malignancy diseases as cited above. Further, many cases of gonosomal aneuploidy patients did not exhibit clonality in our cohort due to random loss and/or few cell used for analysis (25 metaphase plates). FISH and chromosomal rearrangement analysis further are necessary for proper justification.

Regarding acquired autosomal aneuploidy contributed to $45 \%$ (24/53) having trisomy and monosomy 7, 8, 10 and 11 with 3 mosaics followed by double trisomy 8,17 in our report and might be of leukemic cases. Gain of 8 in six cases in our report along with mosaic trisomy 8 could be related to hematologic malignant cases of AML/ CML/ ALL. ${ }^{[18,1]}$ Gain of 8 and 17 could be leukemic related to lymphoproliferative disorders. Similarly such type of AML cases are reported earlier by Garg et al. ${ }^{[41]}$ Further Rubie et al. ${ }^{[42]}$ also detected it in neuroblastoma and breast cancer cases. $^{[43]}$

Gaining of chromosome 11 in two patients and mosaic trisomy 11 in this investigation are related to AML/MDS (Myelodysplastic syndrome) with immature blood cells in bone marrow with abnormal maturation. Gain/ loss of chromosome 10 (2) are also related to ALL and other leukemic disorders respectively. ${ }^{[3]}$ Loss/ gain of chromosomes 7 (10 cases in our report) are related to AML/MDS disorders. ${ }^{[3,44]}$ Mosaic monosomy 7 case found in our study is correlated with blood MDS in pediatric group. Same type of study is reported in a child by Csillag et al. ${ }^{[45]}$ to support our study. Most of the cases in this acquired aneuploidy fall in advancing age (14-88 years). Thus gain and loss of 
chromosomes, including mosaics might lead to cancerous condition in hematologic oncology. ${ }^{[46]}$ Recently it is reported that acquired aneuploidy with AML cases were detected with trisomy 11 followed by patients with multiple chromosomal compliments with MDS. ${ }^{[12]}$ Similarly, sole and clonal aneuploidy cases are documented from our Laboratory ${ }^{[20]}$ from the analysis of leukemic blood to support the present results with advancing age.

The chromosomal mosaic or clonal cases noticed in our congenital and acquired aneuploidy is dependent on numerous factors such as presence of cell lines, cells analyzed andsample type used. It is further dependent on whether in vivo and in vitro selection against on the cell lines occur ${ }^{[4,47,48]}$ supporting our data. Mechanism of genetic mosaicism of chromosomal non-disjunction, infection and environmental factors are too well documented in vitro and in vivo conditions. ${ }^{[3,10,22]}$ Mandrioli et al. ${ }^{[21]}$ proposed that aneuploidy is common biomarker carcinogenesis and reproductive toxicants. Mosaic aneuploidy is also caused by chromosomal instability (CIN) during tumorigenesis. ${ }^{[17,19]}$

Our study implicated that constitutional and acquired chromosomal aneuploidy condition held responsible for genetic diseases and cancer in human. ${ }^{[21]}$ Further detection of these missing or gaining of chromosomes do play a role in ARTs, where couples

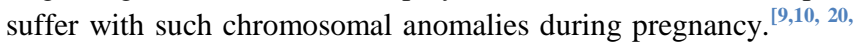
36, 49-53]

\section{Conclusion}

Any chromosomal gain/missing in diploid state leads to aneuploidy with advance age in humans leading to genetic disorders including cancer. In our report $3.7 \%$ of constitutional and acquired aneuploidies were detected. Mosaicism also results in complex genetic anomalies. Such couples are suggested for genetic tests and counseling before adopting reproductive technologies (ARTs) including pre-implantation genetic screening (PGS) and preimplantation genetic diagnosis (PDS).Hence, more scientific research agencies are necessary to organize new strategies for assisting such sufferings.

\section{Recommendation}

This study cohort allows the parents whether it is congenital (constitutional)/acquired chromosomal aneuploidy in humans. Hence such couples make better choice about their future based on their individual risk which has to be our ultimate goal.

\section{Acknowledgement}

Authors are thankful to all laboratory staff of Neuberg Supratech Referral Laboratory, Ahmedabad.

\section{References}

[1] Barch MJ, Knutsen T, Spurbeck J. The AGT Laboratory Manual. Philadelphia, Lippinscott-Raven Publisher, 1997; 3rd Edition.

[2] Verma IC. Burden of Genetic Disorders in India. Ind J Pedia. 2000;67(12): 893-898.

[3] Arsham MS, Barch MJ, Lawce HJ. The AGT Cytogenetics Laboratory Manual, Philadelphia, WileyBlackwell Publisher. 2017; 4thEdition.

[4] Rajasekhar M, Gopinath PM, Sreelakshmi K, Satyamoorthy K. A cytogenetic study of couples with miscarriages: An experience from Manipal Referral Centre.Int J Hum Gen. 2013;13(2): 93-97.

[5] Rajasekhar M,Murugesan R, Rekharao, Shetty H, Jyothirao, Gopinath PM and Satyamoorthy K. Cytogenetic analysis of 1400 referral cases: Manipal experience.Int J of Hum Genet. 2010;10(1-3): 49-55.

[6] Nakamura Y, Kitamura M, Nishimura K, Koga M, Kondoh N, Takeyama M, Matsuymiya K, Okuyama A. Chromosomal variants among 1790 infertile men.Int J of Urol. 2001;8: 49-62.

[7] Bhasin MK. Human Population Cytogenetics: A review. Int J Hum Genet. 2005; 5(2): 83-152.

[8] Harton GL, Tempest HG. Chromosomal disorders and male infertility. Asian J Androl. 2012;4(1) 32-39.

[9] Munne S. Pre-implantation genetic diagnosis of numerical and structural chromosomal abnormalities. RBM Online. 2002;4(2): 183-196.

[10] Shah NP, Shah PS., Bhatt NH, Vaghasia KK, Shah SC, Rao MV. Aneuploidy analysis of 5740 referral cases in relation to sex and autosomes and its relevance to genetic diseases.7thProc Int Symp, Rare Undefined Diseases. New Delhi, Abstract 10. 2019a.

[11] Dey P. Aneuploidy and malignancy: an unresolved problem. J Clin Pathol, 2004;57 (12): 1245-1249.

[12] Vaghasia KK, Bhatt VM, Shah PS, Shah ND, Rao MV, Shah SC. Karyotypic analysis of acute myeloid leukemia (AML) in 75 referral cases: one-year report. Biotechnol Res. 2016; 2(4): 166-168.

[13] Jacobs, P. A., Brown. C.W.M., Doll, R. Distribution of human chromosome counts in relation to age. Nature. 1961; 191(4794), 1178-1180.

[14] Ganmore, I., Smooha, G., \& Izraeli, S. Constitutional aneuploidy and cancer predisposition. Human molecular genetics. 2009;18(R1), R84-R93.

[15] Jackson-Cook C. Constitutional and acquired autosomal aneuploidy. Clinics in laboratory medicine. 2011;1;31(4):481-511.

[16] Weaver BA, Cleveland DW. Does aneuploidy cause cancer. Curr Open Cell Biol. 2006; 18(6): 658-667.

[17] Thomson SL, Bakhourn SF, Compton DA. Mechanism of chromosomal instability. Curr Biol. 2010; 20(6), R265-R295.

[18] Bakshi RS, Brahmbhatt MM, Trivedi PJ Dalal PN, Patel DM, Purani SS, Shukla SN, Shah PM, Patel PS. 2012. Trisomy 8 in leukemia: A GCRI experience. Ind J Hum Genet.18(1): 106-108.

[19] Jain S. Colon Tumor Mechanism Pathway's Chromosomal Instability Pathway.The Ohio State University, Wexner Medical Center. 2019.

[20] Shah NP, Shah PS, Bhatt NH, Mistry K, Dominic J, Kansara M, Hakim S, Shah SC, Rao MV. Detection of sole and clonal aneuploidy in hematologic malignant diseases. Biotechnological Res. 2019 b ;35: 16-21.

[21] Mandrioli D, Belpoggi F, Silbergold EK, Perry MJ. Aneuploidy. A common and early evidence -based biomarker for carcinogenesis and reproductive toxicants. Environ Health. 2016;15(1): 97-101.

[22] Xu J, Zhu R, Fan L, Ge S, We w, Li X, Da L, Jia Z, Ninoj, J Da J, Peng W, Gu K, Sun G. Prognostic value of DNA aneuploidy in gastric cancer. A meta-analysis of 3449 cases. BMC Cancer. 2019; 19(1): 650-658. 
[23] Jordan JW, Simmons A, Schmid M. An International System for Human Cytogenetic Nomenclature (ISCN), Basel, Karger Publications. 2016.

[24] Vaghasia KK, Shah DN, Bhatt VM, Shah PS, Rao MV, Shah SC. Cytogenetic analysis of Down syndrome: A report from India. Int J App Biol Pharmaceutical Tech. 2017; 8: 43-47.

[25] Gilany EL, Yahia S, Shokar M, Dahtory EL. Cytogenetic and co-morbidity profile of Down syndrome in Mansourya University Children's Hospital. Int J Hum Genet. 2011;17(3): 157-163.

[26] Shah VC. Essentials of Modern Genetics, Ahmedabad, Nirav Prakasan Publications. 1997.

[27] Papp Z, Osztovics M, Schuler D, Mehes K, Czeizel E, Horvath L, Szemere G, Laszlo J. Down's syndrome chromosome analysis of 162 cases in Hungary.Hum Hered. 1977;27: 305-309.

[28] Fishler, K, and Koch, R. Mental development in Down syndrome mosaicism. American Journal on Mental Retardation. 1991; 96(3), 345-351.

[29] Satgé D, Nishi M, Sirvent N, Chenard MP, Barnes A, Vekemans M. A tumor profile in Patau syndrome (trisomy 13). American JMedi Gen. 2017;9999: 1-9.

[30] Santana-Davila R., Ellliot M, Hook C, Kaufmann S, Letendre L, Pruthi R, Tefferi A, Van Dyke D, Wiktor A, Litzow MR. Trisomy 13 in patients with hematological malignancies. J Clin Oncology. 2007;25(18): 7055.

[31] Herold T, Metzeler KH, Vosberg S, Hartmann L, Röllig C, Stölzel F, Schneider S, Hubmann M, Zellmeier E, Ksienzyk B, Jurinovic V. Isolated trisomy 13 defines a homogeneous AML subgroup with high frequency of mutations in spliceosome genes and poor prognosis. Blood, The Journal of the American Society of Hematology. 2014;21;124(8):1304-11.

[32] McDonald WN, Rennie A, Tolmie J, Galloway P, McWilliam R. Investigation of global developmental delay. Arch. Of Disease in Childhood. 2006;91: 701-705.

[33] Peroose, S., Forsythe, E., Pugh, J. H., Arthur-Farraj, P., and Hodes, D. Longevity and Patau syndrome: what determines survival? Case Reports. 2012, bcr0620114381.

[34] Rasmussen JA, Wong LY, Yang G, May KM, Friedman JM. Population based analysis of mortality in trisomy 13 and trisomy 18. Pediatrics. 2003; 111: 777-784.

[35] Ten SK, Chun YM, Noor JP, Hassan R. Cytogenetic studies in women with primary amenorrhea.Sing Med J. 1990;31: 355-359.

[36] Zhao X, Shen GM, Feng Q, Jun XG, Luo Y. A cytogenetic study of 131 patients with primary amenorrhea including 3 abnormal karyotypes. YI Chuan. 2008;30(8): 996-1002.

[37] Catzi-Parasidou A, Chrostoforidis N, Samolado G, Nijs M. Sperm aneuploidy in infertile patients. A systematic review of the literature. 2015;Andrologia.47(8): 847860.

[38] Handyside AH. Preimplantation genetic diagnosis after 20 years. Reprod.Biomed 0nline. 2010;21: 280-282.

[39] Piomboni P, Stendardi S, Gambera L. Chromosomal aberrations and aneuploidies of spermatozoa. Adv Exp Med Biol. 2014; 791: 27-52.

[40] Mengual EG, Trivino JC, Cuevas AS, Bataller T, Jorro MR, Vendrell X. Male infertility: establishing sperm aneuploidy thresholds in the laboratory. J Asstd Reprod Genet. 2019;36(3): 371-381.

[41] Garg M, Nagata Y, Kanojia D, Mayakonda A, Yoshida K, Haridas Keloth S, Zang ZJ, Okuno Y, Shiraishi Y, Chiba K, Tanaka H. Profiling of somatic mutations in acute myeloid leukemia with FLT3-ITD at diagnosis and relapse. Blood, The Journal of the American Society of Hematology. 2015;26;126(22):2491-501.

[42] Rubie H, Plantaz D, Michon J, Chastagner P, Coze C, Baranzelli MC. Localized neuroblastoma: N-myc gene amplification is the main prognostic factor and postoperative treatment can be deleted in infants. Med Pediatr Oncol. 1993;21: 582.

[43] Bilal E, Dutkowski J, Guinney J, Jang IS, Logsdon BA, Pandey G, Sauerwine BA, Shinone Y, Vollan HKM, Mecham BH, Rued MO, Tost J, Curtis C, Alvarez MJ, Kristensen VN, Apuricia S, Dale BAL, Caldas C, Califano A, Friend SH, Ideker T, Sehad EE, Stolovitzky AG, Margolin AA. Improving breast cancer survival analysis through competition-based multidimensional modeling. PLOS Computational Biol. 2013;9(5): 1-16 e1003047.

[44] Morrissette JJ, Wertheim G, Olson T. Familial monosomy 7 syndrome. InGeneReviews ${ }^{\circledR}[$ Internet]. University of Washington, Seattle. 2016.

[45] Csillag B, Ilencikova D, Meissl M, Webersinke G, Laccone F, Narumi S, Haas O, Duba HC. Somatic mosaic monosomy 7 and UPD7q in a child with MIRAGE syndrome caused by a novel SAMD9 mutation. Pediatric blood \& cancer. 2019;66(4):e27589.

[46] Rowley JD, Testa JR. Chromosomal abnormalities inmalignant hematologic diseases.Adv Can Res. 1982; 36: 103-148.

[47] Kalavathi V, Chandra N, Nambiar GR, Shanker J, Sugunashankari J, Meena T, Jagatheesan T, Santhiya ST, Ramesh K, Gopinath PM, Marimuthu KM. Chromosomal abnormalities in979 cases of amenorrhea: A review. Int J Hum Genet. 2010;10 (1-3): 65-69.

[48] Jyothy A, Kumar KSD, Swarna M, Rajasekhar M, Umadevi B, Reddy PP. Cytogenetic investigations of 1843 normal cases of disordered sexual development from Andhra Pradesh, India. Int J Hum Genet. 2002;2: 55-59.

[49] Marquez C, Sandalines M, Bahce M, Alkani M, Munne S. Chromosomal abnormalities in 1255 cleavage-stage human embryos.RBM Online. 2000;1(1): 17-26.

[50] Simpson JL. Preimplantation genetic diagnosis at 20 years. Prenatal diagnosis. 2010;30(7): 682-95.

[51] Sullivan-Pyke C, Dokras A. Preimplantation screening and preimplantation genetic diadnosis. Obstet Gynecol Clin North A. 2018; 45(1): 113-125.

[52] Minasi MG, Fiorentino F, Ruberti A, Biricik A, Cursio E, Cotronio E, Varricchio MT, Surdo M, Spenella, F, Greco E. Genetic diseases and aneuploidies can be detected with single blastocyst biopsy: a successful clinical approach. Human Reprod. 2017; 32(8): 17701777.

[53] Fischer J, Calis P, Escudero T, Munne S. Preimplantation genetic diagnosis (PGD) improves pregnancy outcome for translocation carriers with a history of recurrent losses. Fertil Steril. 2010;94: 283-289 